\title{
Relation similarity as a function of agreement between relation elements
}

\author{
TERESA STASIO and DOUGLAS J. HERRMANN \\ Hamilton College, Clinton, New York
}

and

ROGER CHAFFIN

Trenton State College, Trenton, New Jersey

\begin{abstract}
People perceive that semantic relations vary in similarity to each other. For example, when subjects sorted pairs representing 31 relations into groups of similar relations, the sorting frequencies indicated that the subjects grouped together relations that had similar definitions (Chaffin \& Herrmann, 1984). Consequently, it was hypothesized that people judge the similarity between relations on the basis of agreement in the elements that, according to linguistic theory, make up these relations. To test this hypothesis, the present research correlated the sorting frequencies from the Chaffin and Herrmann study with estimates of relation similarity derived from relation element agreement. A significant correlation $(r=.707)$ was found between the two variables, indicating that perceptions of relation similarity are derived from the amount of agreement between relations in their relation elements.
\end{abstract}

People perceive a variety of relations among words; for example, two words may be related by antonymy, synonymity, or class inclusion. People also perceive that relations vary in how much they resemble each other; for example, class inclusion (robin-bird) is seen as more similar to synonymity (car-auto) than either relation is to antonymy (affluence-poverty). Linguists claim that relations are each defined differently, but that the definition of one relation may share some of the elements of the definition of another relation; for example, synonymity and class inclusion both involve denotative agreement but not the denotative opposition of antonymy. The purpose of the present research was to ascertain whether perceptions of relation similarity originate in a comparison of relational elements similar to those used in linguistics to define relations (Leech, 1974; Lyons, 1968, 1977). If it could be shown that perceptions of relation similarity vary with the overlap in relation definitions, then the theory that the comprehension of relations involves processing definitional elements of relations would gain further support (Chaffin \& Herrmann, 1984a, 1984b; Johnson-Laird, Herrmann, \& Chaffin, 1984; see also Klix, Hoffman, \& van der Meer, 1983).

A recent study (Chaffin \& Herrmann, 1984b) showed that relation similarity varies systematically across relations. The study required subjects to sort word pairs that represented 31 relations into groups of similar relations. The names of these 31 relations and examples of them

\footnotetext{
The authors thank George Gescheider and Jonathan Vaughan for helpful comments on an earlier draft of this article. Requests for reprints should be sent to Douglas J. Herrmann, Department of Psychology, Hamilton College, Clinton, NY 13323.
}

are presented in the first two columns of Table 1. The sorting frequencies indicated three aspects of subjects' perceptions of relation similarity. First, subjects perceived relations as falling into five families of similar relation (listed in Table 1). Second, families were perceived to vary in relation similarity to each other (e.g., similars and class inclusion relations were seen as more similar to each other than to contrast relations). Third, subjects' perceptions of relation similarity varied within a family; for example, opposites such as hot-cold were sorted more frequently together with opposites such as alive-dead than either were with opposites such as frank-hypocritical.

The three ways that relation similarity varied in Chaffin and Herrmann's (1984b) study were explained as being due to agreement of elements that define relations. For example, subjects frequently sorted pairs such as alive-dead with those such as hot-cold because both pairs shared the antonym elements of (1) a common dimension on which word meanings are represented (2) bilaterally and (3) symmetrically about the dimension's midpoint; however, neither pair was sorted with synonyms (carauto), since synonymity is not defined by a common dimension with symmetric opposition. However, this explanation was only speculative; consequently, it seemed appropriate to test whether agreement in relation elements might actually account for the relation-similarity data.

In order to provide an explicit test of the elementagreement hypothesis of relation similarity, it is necessary to develop a precise linguistic account of the relation elements required by the 31 relations in the Chaffin and Herrmann (1984b) study. Table 2 presents such a list of relation elements, and Table 1 presents in its third column the way in which these elements enter into each 
Table 1

Semantic Relations and Their Relation Elements

\begin{tabular}{|c|c|c|}
\hline Relations by Families & Examples & Relation Elements \\
\hline \multicolumn{3}{|l|}{ I. CONTRASTS } \\
\hline $\begin{array}{l}\text { Pseudoantonyms } \\
\text { Contradictory } \\
\text { Contrary } \\
\text { Directional } \\
\text { Reverse } \\
\text { Asymmetric Contrary } \\
\text { Incompatible } \\
\text { Attribute Similarity }\end{array}$ & $\begin{array}{l}\text { Popular-Shy, Generous-Poor } \\
\text { Alive-Dead, Remember-Forget } \\
\text { Old-Young, Smooth-Rough } \\
\text { Front-Back, Left-Right } \\
\text { Buy-Sell, Attack-Defend } \\
\text { Hot-Cool, Large-Tiny } \\
\text { Frank-Hypocritical, Happy-Morbid } \\
\text { Rake-Fork, Valley-Gutter }\end{array}$ & $\begin{array}{l}\text { Dim, BiP, Con } \\
\text { Dim, BiP, Dich, Sym } \\
\text { Dim, BiP, Cont, Sym } \\
\text { Dim, BiP, Dich, Spa } \\
\text { Dim, BiP, Dich, Vec } \\
\text { Dim, BiP, Cont } \\
\text { Dim, BiP } \\
\text { Over, Int, Att, Dis }\end{array}$ \\
\hline \multicolumn{3}{|l|}{ II. SIMILARS } \\
\hline $\begin{array}{l}\text { Action Subordinate } \\
\text { Dimensional Similarity } \\
\text { Synonymity } \\
\text { Necessary Attribution } \\
\text { Invited Attribution }\end{array}$ & $\begin{array}{l}\text { Cook-Fry, Clean-Scrub } \\
\text { Smile-Laugh, Hungry-Starving } \\
\text { Purchase-Buy, Car-Auto } \\
\text { Bachelor-Unmarried, Tower-High } \\
\text { Food-Tasty, Bed-Comfortable }\end{array}$ & $\begin{array}{l}\text { Inc, Int, UniI } \\
\text { Over, Int, Dim, UniP } \\
\text { Inc, Int, Bil } \\
\text { Over, Int, Att, Poss } \\
\text { Inc, Con, Att, Poss }\end{array}$ \\
\hline \multicolumn{3}{|l|}{ III. CLASS INCLUSION } \\
\hline $\begin{array}{l}\text { State Subordinate } \\
\text { Functional Subordinate } \\
\text { Activity Subordinate } \\
\text { Perceptual Subordinate } \\
\text { Place } \\
\text { Geographical Subordinate }\end{array}$ & $\begin{array}{l}\text { Disease-Polio, Emotion-Fear } \\
\text { Furniture-Chair, Vehicle-Car } \\
\text { Game-Chess, Crime-Theft } \\
\text { Animal-Horse, Flower-Rose } \\
\text { Germany-Hamburg, Asia-China } \\
\text { Country-Russia, Continent-America }\end{array}$ & $\begin{array}{l}\text { Inc, Int, UniI } \\
\text { Inc, Int, UniI } \\
\text { Inc, Int, UniI } \\
\text { Inc, Int, UniI } \\
\text { Inc, Poss, Partive, Loc } \\
\text { Inc, Int, UniI }\end{array}$ \\
\hline \multicolumn{3}{|l|}{ IV. CASE RELATIONS } \\
\hline $\begin{array}{l}\text { Action-Recipient } \\
\text { Action-Instrument } \\
\text { Agent-Action } \\
\text { Agent-Instrument } \\
\text { Agent-Object }\end{array}$ & $\begin{array}{l}\text { Sit-Chair, Hunt-Prey } \\
\text { Drink-Cup, Cut-Knife } \\
\text { Dog-Bark, Artist-Paint } \\
\text { Farmer-Tractor, Soldier-Gun } \\
\text { Baker-Bread, Carpenter-Lumber }\end{array}$ & $\begin{array}{l}E v t, \text { Act, Obj } \\
E v t, \text { Act, Inst } \\
E v t, \text { Act, Agent } \\
E v t, \text { Agent, Inst } \\
\text { Evt, Agent, Obj }\end{array}$ \\
\hline \multicolumn{3}{|l|}{ V. PART-WHOLES } \\
\hline $\begin{array}{l}\text { Measure } \\
\text { Ingredients }\end{array}$ & $\begin{array}{l}\text { Mile-Yard, Hour-Minute } \\
\text { Pizza-Cheese, Table-Wood }\end{array}$ & $\begin{array}{l}\text { Inc, Homo, Partive } \\
\text { Inc, Prop, Poss, Comp, } \\
\text { Loc, Partive }\end{array}$ \\
\hline Collection & Forest-Tree, Fleet-Ship & $\begin{array}{l}\text { Inc, Prop, Homo, Poss, } \\
\text { Partive }\end{array}$ \\
\hline Group & Choir-Singer, Faculty-Professor & $\begin{array}{l}\text { Inc, Prop, Soc, Homo, } \\
\text { Poss, Partive }\end{array}$ \\
\hline Functional-Location & Car-Engine, House-Roof & $\begin{array}{l}\text { Inc, Prop, Attach, Poss, } \\
\text { Comp, Partive }\end{array}$ \\
\hline Functional Location & House - Dining Room, Kitchen-Refrigerator & $\begin{array}{l}\text { Inc, Attach, Prop, Poss, } \\
\text { Comp, Partive }\end{array}$ \\
\hline Organization & Army - Supply Corps, Government - Executive Branch & $\begin{array}{l}\text { Inc, Prop, Soc, Attach, } \\
\text { Poss, Comp, Partive }\end{array}$ \\
\hline
\end{tabular}

Note-The relations in this table are those used in Chaffin and Herrmann's (1984b) sorting study. The table presents these relations according to family and in the order of presentation in the hierarchical clustering solution of the sorting data. All relations in the table involve the element of denotative agreement in addition to the elements shown. For the definitions of the relation elements, see Table 2.

of the 31 relations. The elements were derived from detailed analyses given in standard linguistic sources (Evens, Litowitz, Markowitz, Smith, \& Werner, 1983; Leech, 1974; Lyons, 1968, 1977). Linguistic investigation into some of these relations is new; thus, some of these definitions represent only a first approximation to the definitions that will eventually be settled on. The definitions in Table 1 may be interpreted with the aid of Table 2 . For example, a contrary antonym is defined as having the relation elements of dimensional meaning, continuous dimension, and symmetric bilateral position on a dimension (e.g., " hot-cold"); these elements constitute the standard linguistic definition of contraries (Herrmann, Chaffin, Conti, Peters, \& Robbins, 1979).
Comparison of the definitions in Table 1 suggests that relation-element agreement accounts for the salient results of Chaffin and Herrmann's (1984b) study. First, the relation elements differ markedly between families. Second, the overlap in relation elements across families is partially consistent with the sorting data. For example, the similars and class-inclusion families share approximately two elements and were occasionally sorted together. Third, the agreement in elements between relations within a family appears to be consistent with the sorting data; for example, the definitions of necessary and invited attribution agree more with each other than either of these relations agrees with synonymity.

Table 1 , besides allowing a qualitative evaluation of the 
Table 2

Relation Elements and Their Definitions

\begin{tabular}{|c|c|c|}
\hline Relation Elements & Definition & Description \\
\hline \multicolumn{3}{|l|}{ I. Elements of Intensional Force } \\
\hline $\begin{array}{l}\text { Denotative (Den) } \\
\text { Connotative (Con) }\end{array}$ & $\begin{array}{l}\text { Wi \& Wj share denotative meaning } \\
\text { Wi connotes } \mathrm{Wj}\end{array}$ & $\begin{array}{l}\text { referential sense } \\
\text { affective sense }\end{array}$ \\
\hline \multicolumn{3}{|l|}{ II. Propositional Elements } \\
\hline $\begin{array}{l}\text { Attributive (Att) } \\
\text { Property (Prop) } \\
\text { Componential (Comp) } \\
\text { Social (Soc) } \\
\text { Homogenous (Homo) } \\
\text { Attachment (Attach) } \\
\text { Possession (Poss) } \\
\text { Agentive (Agent) } \\
\text { Objective (Obj) } \\
\text { Instrumental (Inst) } \\
\text { Action (Act) } \\
\text { Event (Evt) }\end{array}$ & $\begin{array}{l}\text { Wi "is" Wj } \\
\text { Wi "has"' Wj } \\
\text { Wi is a component of Wj } \\
\text { Wi is socially committed to } W j \\
\text { Wi's referent is indistinguishable from Wj's referent } \\
\text { Wi's referent is attached to Wj's referent } \\
\text { Wi belongs to Wj } \\
\text { Wi acts on/to/for Wj } \\
\text { Wi is an object of/to/for Wj } \\
\text { Wi acts as an instrument for Wj } \\
\text { Wi is action bearing to/for/on Wj } \\
\text { Wi pertains to an event involving Wj }\end{array}$ & $\begin{array}{l}\text { must (can) be like } \\
\text { property of } \\
\text { partial makeup of } \\
\text { social contract } \\
\text { indistinguishable } \\
\text { is attached to } \\
\text { owned/possessed by } \\
\text { agentive power } \\
\text { object status } \\
\text { instrumental power } \\
\text { action bearing } \\
\text { event bearing }\end{array}$ \\
\hline \multicolumn{3}{|l|}{ III. Dimensional Elements } \\
\hline $\begin{array}{l}\text { Dimension (Dim) } \\
\text { Unilateral Position (UniP) } \\
\text { Bilateral Position (BiP) } \\
\text { Symmetrical Position (Sym) } \\
\\
\text { Continuous (Cont) } \\
\text { Discrete (Dis) } \\
\text { Dichotomous (Dich) } \\
\text { Spatial (Spa) } \\
\text { Vector (Vec) }\end{array}$ & $\begin{array}{l}\text { Wi \& Wj share a single dimension } \\
\mathrm{Wi} \& \mathrm{Wj} \text { are on the same sides of the midpoint } \\
\mathrm{Wi} \& \mathrm{Wj} \text { are on opposite sides of the midpoint } \\
\mathrm{Wi} \text { is of = magnitude to } \mathrm{Wj} \\
\mathrm{Wi} \& \mathrm{Wj} \text { can be qualified } \\
\mathrm{Wi} \& \mathrm{Wj} \text { cannot be qualified } \\
\text { If Wi then not Wj } \\
\text { Wi is spatially opposite } \mathrm{Wj} \\
\text { Wi is directionally opposed to } \mathrm{Wj}\end{array}$ & $\begin{array}{l}\text { dimensional commonality } \\
\text { same side of midpoint } \\
\text { opposing magnitudes } \\
\text { equidistant from } \\
\text { midpoint } \\
\text { gradable } \\
\text { nongradable } \\
\text { mutually exclusive } \\
\text { opposed in space } \\
\text { directionally oriented }\end{array}$ \\
\hline \multicolumn{3}{|l|}{ IV. Elements of Agreement } \\
\hline $\begin{array}{l}\text { Inclusion (Inc) } \\
\text { Overlap (Over) } \\
\text { Intersection (Int) } \\
\text { Unilateral Inclusion (UniI) } \\
\text { Bilateral Inclusion (BiI) } \\
\text { Locative Inclusion (Loc) } \\
\text { Partive Inclusion (Partive) } \\
\end{array}$ & $\begin{array}{l}\text { Wi is included in } W j \\
W i \text { is partially included in } W j \\
W i \text { is semantically included in } W j \\
W j \text { includes all of Wi, but Wi does not include all of } W j \\
W i=W j \\
\text { Wi's referent is dependent on Wj's referent } \\
\text { Wi is literally part of Wj }\end{array}$ & $\begin{array}{l}\text { general inclusion } \\
\text { overlap in meaning } \\
\text { semantic inclusion } \\
\text { partial inclusion } \\
\text { total inclusion } \\
\text { locational restraint } \\
\text { parts of }\end{array}$ \\
\hline
\end{tabular}

relation-element explanation of relation similarity, permits quantitative tests of this explanation. A measure of relation similarity was computed for each pair of relations on the basis of the proportion of shared elements. If relation similarity is based on the number of shared relation elements, then there should be a significant correlation between the sorting data reported by Chaffin and Herrmann (1984b) and each of the relation-similarity estimates.

\section{METHOD}

\section{Relation-Similarity Sorting Frequencies}

The sorting data collected by Chaffin and Herrmann (1984b) were represented in a matrix ( 31 relations $\times 31$ relations) such that each cell of the matrix contained the number of subjects who sorted into the same pile the two relations defining a cell. Since sorting data do not separate directional differences in similarity (i.e., Relation 1 to Relation 2 vs. Relation 2 to Relation 1), these data fill only half of the matrix (which included 465 cells). The Chaffin and Herrmann report did not present this matrix directly, but, instead, presented the hierarchical clustering solution (HICLUS) that was derived from the matrix.

\section{Estimates of Relation Similarity From Relation Definitions}

The relation similarity for each pair in the matrix was estimated by the mean of the overall number of elements that were in agreement be- tween the relations over each relation's elements; that is, similarity = $\left[\left(A / R_{1}\right)+\left(A / R_{2}\right)\right] / 2$. It should be noted that, in order to simplify the analysis, the equation did not take into account the hierarchical structure of elements defining relations (e.g., that two words must share a dimension before they can be opposed).

\section{RESULTS AND DISCUSSION}

The correlation of the sorting data with the similarity estimate was .707 ( $\mathrm{df}=463, \mathrm{p}<.001)$. Additional analyses were carried out to determine how well relation-element agreement correlates with the three specific aspects of the clustering analysis reported by Chaffin and Herrmann (1984b): that relations were perceived to be most similar within a family, that families varied in similarity to one another, and that relations within a family varied in similarity to each other. To assess how much of the variance was accounted for by the defining elements of a family, a family-similarity matrix was computed. Similarity estimates were assigned a value of 1 when a pair of relations came from the same family, as defined by relation definitions (family elements are in italics in Table 1). Estimates were assigned a value of 0 
when the pair came from different families. The familybased correlation was, as expected from the HICLUS solution in Chaffin and Herrmann (1984b), substantial: r(463) $=.691(\mathrm{p}<.001)$. A partial correlation of relation similarity and relation-element agreement with familyelement agreement held constant was .355 (df $=461$, p $<.001$ ), showing that some of the variance in the sorting data cannot be accounted for by agreement of family elements within a family.

To assess how well relation-element agreement accounts for the similarity of families to each other, the sorting frequencies were correlated with element agreement for relations from different families $[\mathrm{r}(378)=.399, \mathrm{p}<.001]$. Inspection of Table 1 indicates that this correlation is due to interfamily agreement for similars and class inclusion, as well as to agreement on general inclusion between partwhole inclusion and class inclusion.

In order to assess how well relation-element agreement accounts for relation similarity within families, the sorting data and similarity estimates were correlated for each of the five families separately. These correlations by family were: contrasts $[\mathrm{r}(28)=.751, \mathrm{p}<.001]$; similars $[\mathrm{r}(10)=.517, \mathrm{p}<.07]$; class inclusion $[\mathrm{r}(15)=.535$, $\mathrm{p}<.05]$; case relations $[\mathrm{r}(10)=.445, \mathrm{p}<.10]$; and part-whole relations $[\mathrm{r}(21)=.329, \mathrm{p}<.08]$. Although three of these correlations were not significant $(p \leq .05)$, the general pattern of results indicates that sorting within families may be accounted for by relation-agreement.

It might be argued that the relation elements used here are not genuine components of relation definitions but are ad hoc. However, careful examination of the semanticrelations literature will show that the definitions in Table 1 coincide closely with current linguistic accounts of relation definitions (Leech, 1974; Lyons, 1968, 1977; see also Evens et al., 1983); relation-element agreement does predict relation-similarity data.

It may be argued that other models provide better accounts of relation-similarity data. Network theories, it might be supposed, could do so. However, these theories are totally incapable of accounting for relation similarity because the links representing relations in networks are assumed to be unanalyzable and unique (Johnson-Laird et al., 1984).

In addition, it might be argued that a variant of a featurecomparison model can generate a better account of the sorting data than that generated by relation elements. These models assume that relations are apprehended merely from the computation of overlap of meanings in a word pair (Smith \& Medin, 1981). Obviously, overlap alone cannot indicate the degree to which relations resemble one another; for example, the meanings of car-engine have nothing in common with the meanings of housekitchen, yet these pairs clearly possess similar relation definitions.

Thus, the best account of relation similarity is provided by a model in which relation similarity is derived from the agreement in the elements that define relations. This conclusion is consistent with evidence that relationsimilarity ratings and the latency and accuracy of relation judgements rest on processing stimuli according to how well their relational properties conform to the elements defining task relations (Chaffin \& Herrmann, 1984b; Johnson-Laird et al., 1984). It is becoming increasingly apparent that an adequate theory of relation comprehension must base processing totally or partly on the elements of relations.

\section{REFERENCES}

Chaffin, R., \& Herrmann, D. J. (1981). Semantic relationships and the generality of semantic memory models. Bulletin of the Psychonomic Society, 17, 69-72.

Chaffin, R., \& Herrmann, D. J. (1984a). Relation element theory. Unpublished manuscript.

Chaffin, R., \& Herrmann, D. J. (1984b). The similarity and diversity of semantic relations. Memory \& Cognition, 12, 134-141.

Evens, M. W., Litowitz, D. E., Markowitz, J. A., Smith, R. N., \& WERNER, O. (1983). Lexical-semantic relations: A comparative survey (Current Inquiry into Language and Linguistics No. 34). Carbondale, IL, and Edmonton, Canada, Linguistic Research, Inc.

Herrmann, D. J., Chaffin, R., Conti, G., Peters, D., \& Robbins, P. H. (1979). Comprehension of antonymy and the generality of categorization models. Journal of Experimental Psychology: Human Learning and Memory, 5, 585-597.

Johnson-Laird, P. N., Herrmann, D. J., \& Chaffin, R. (1984). Only connections: A critique of semantic networks. Psychological Bulletin, 96, 292-315.

Klix, F., Hoffman, J., \& VAN Der Meer, E. (1983). Le stockage de concepts et leur utilisation cognitive. Bulletin de Psychologie, 35, 533-543.

LeECH, G. N. (1974). Semantics. Harmonsworth, England: Penguin. Lyons, J. (1968). Introduction to theoretical linguistics. Cambridge, England: Cambridge University Press.

LyONs, J. (1977). Semantics (Vol. 1). Cambridge, England: Cambridge University Press.

Smith, E. E., \& Medin, D. L. (1981). Categories and concepts. Cambridge, MA: Harvard University Press.

(Manuscript received for publication August 29, 1984.) 